\title{
Impaired basal glucose effectiveness but unaltered fasting glucose release and gluconeogenesis during short-term hypercortisolemia in healthy subjects Michael F. Nielsen, Andrea Caumo, Visvanathan Chandramouli, William C. Schumann, Claudio Cobelli, Bernard R. Landau, Hendrik Vilstrup, Robert A. Rizza and Ole Schmitz \\ Am J Physiol Endocrinol Metab 286:E102-E110, 2004. First published 9 September 2003; doi:10.1152/ajpendo.00566.2002
}

You might find this additional info useful...

This article cites 45 articles, 25 of which can be accessed free at: http://ajpendo.physiology.org/content/286/1/E102.full.html\#ref-list-1

This article has been cited by 3 other HighWire hosted articles

Cross-Sectional and Longitudinal Changes of Glucose Effectiveness in Relation to Glucose Tolerance : The Insulin Resistance Atherosclerosis Study

Carlos Lorenzo, Lynne E. Wagenknecht, Andrew J. Karter, Anthony J.G. Hanley, Marian J.

Rewers and Steven M. Haffner

Dia Care, September, 2011; 34 (9): 1959-1964.

[Abstract] [Full Text] [PDF]

Effect of 11 $\beta$-hydroxysteroid dehydrogenase-1 inhibition on hepatic glucose metabolism in the conscious dog

Dale S. Edgerton, Rita Basu, Christopher J. Ramnanan, Tiffany D. Farmer, Doss Neal, Melanie

Scott, Peer Jacobson, Robert A. Rizza and Alan D. Cherrington

Am J Physiol Endocrinol Metab, May , 2010; 298 (5): E1019-E1026.

[Abstract] [Full Text] [PDF]

PCB126 Induces Differential Changes in Androgen, Cortisol, and Aldosterone Biosynthesis in Human Adrenocortical H295R Cells

Lih-Ann Li and Pei-Wen Wang

Toxicol. Sci., May , 2005; 85 (1): 530-540.

[Abstract] [Full Text] [PDF]

Updated information and services including high resolution figures, can be found at:

http://ajpendo.physiology.org/content/286/1/E102.full.html

Additional material and information about AJP - Endocrinology and Metabolism can be found at: http://www.the-aps.org/publications/ajpendo

This infomation is current as of September 6, 2011.

AJP - Endocrinology and Metabolism publishes results of original studies about endocrine and metabolic systems on any level of organization. It is published 12 times a year (monthly) by the American Physiological Society, 9650 Rockville Pike, Bethesda MD 20814-3991. Copyright @ 2004 by the American Physiological Society. ISSN: 0193-1849, ESSN: 1522-1555. Visit our website at http://www.the-aps.org/. 


\title{
Impaired basal glucose effectiveness but unaltered fasting glucose release and gluconeogenesis during short-term hypercortisolemia in healthy subjects
}

\author{
Michael F. Nielsen, ${ }^{1,3}$ Andrea Caumo, ${ }^{4}$ Visvanathan Chandramouli, ${ }^{6}$ William C. Schumann, ${ }^{6}$ \\ Claudio Cobelli, ${ }^{5}$ Bernard R. Landau, ${ }^{6}$ Hendrik Vilstrup, ${ }^{2}$ Robert A. Rizza, ${ }^{7}$ and Ole Schmitz ${ }^{1}$ \\ ${ }^{1}$ Department of Endocrinology, Aarhus Kommunehospital and Department of Clinical Pharmacology, University of \\ Aarhus, ${ }^{2}$ Department of Medicine V, Aarhus University Hospital, and ${ }^{3}$ Department of Surgical Gastroenterology L, \\ Aarhus Kommunehospital, DK-8000 Aarhus, Denmark; ${ }^{4}$ Metabolism and Nutrition Unit, San Raffaele Scientific \\ Institute, 20132 Milan, and ${ }^{5}$ Department of Electronics and Informatics University of Padova, 35128 Padua, Italy; \\ ${ }^{6}$ Department of Medicine, Case Western Reserve University School of Medicine, Cleveland, Ohio 44106; and \\ ${ }^{7}$ Endocrine Research Unit, Mayo Clinic, Rochester, Minnesota 55905
}

Submitted 23 December 2002; accepted in final form 8 September 2003

\begin{abstract}
Nielsen, Michael F., Andrea Caumo, Visvanathan Chandramouli, William C. Schumann, Claudio Cobelli, Bernard R. Landau, Hendrik Vilstrup, Robert A. Rizza, and Ole Schmitz. Impaired basal glucose effectiveness but unaltered fasting glucose release and gluconeogenesis during short-term hypercortisolemia in healthy subjects. Am J Physiol Endocrinol Metab 286: E102-E110, 2004. First published September 9, 2003; 10.1152/ajpendo.00566.2002.-Excess cortisol has been demonstrated to impair hepatic and extrahepatic insulin action. To determine whether glucose effectiveness and, in terms of endogenous glucose release (EGR), gluconeogenesis, also are altered by hypercortisolemia, eight healthy subjects were studied after overnight infusion with hydrocortisone or saline. Glucose effectiveness was assessed by a combined somatostatin and insulin infusion protocol to maintain insulin concentration at basal level in the presence of prandial glucose infusions. Despite elevated insulin concentrations $(P<0.05)$, hypercortisolemia resulted in higher glucose
\end{abstract} $(P<0.05)$ and free fatty acid concentrations $(P<0.05)$. Furthermore, basal insulin concentrations were higher during hydrocortisone than during saline infusion $(P<0.01)$, indicating the presence of steroidinduced insulin resistance. Postabsorptive glucose production $(P=$ $0.64)$ and the fractional contribution of gluconeogenesis to EGR $(P=$ 0.33 ) did not differ on the two study days. During the prandial glucose infusion, the integrated glycemic response above baseline was higher in the presence of hydrocortisone than during saline infusion $(P<$ $0.05)$, implying a decrease in net glucose effectiveness $(4.42 \pm 0.52$ vs. $\left.6.65 \pm 0.83 \mathrm{ml} \cdot \mathrm{kg}^{-1} \cdot \mathrm{min}^{-1} ; P<0.05\right)$. To determine whether this defect is attributable to an impaired ability of glucose to suppress glucose production, to stimulate its own uptake, or both, glucose turnover and "hot" (labeled) indexes of glucose effectiveness (GE) were calculated. Hepatic GE was lower during cortisol than during saline infusion $\left(2.39 \pm 0.24\right.$ vs. $3.82 \pm 0.51 \mathrm{ml} \cdot \mathrm{kg}^{-1} \cdot \mathrm{min}^{-1} ; P<$ $0.05)$, indicating a defect in the ability of glucose to restrain its own production. In addition, in the presence of excess cortisol, glucose disappearance was inappropriate for the prevailing glucose concentration, implying a decrease in glucose clearance $(P<0.05)$. The decrease in glucose clearance was confirmed by the higher increment in $\left[3-{ }^{3} \mathrm{H}\right]$ glucose during hydrocortisone than during saline infusion $(P<0.05)$, despite the administration of identical tracer infusion rates. In conclusion, short-term hypercortisolemia in healthy individuals with normal $\beta$-cell function decreases insulin action but does not alter rates of EGR and gluconeogenesis. In addition, cortisol impairs the ability of glucose to suppress its own production, which due to accumulation of glucose in the glucose space results in impaired peripheral glucose clearance. These results suggest that cortisol excess

Address for reprint requests and other correspondence: M. F. Nielsen, Dept. of Surgical Gastroenterology L, Aarhus Univ. Hospital, Aarhus Kommunehospital, DK-8000 Aarhus C, Denmark (E-mail: nielsenm@post7.tele.dk). impairs glucose tolerance by decreasing both insulin action and glucose effectiveness.

insulin action

EXCESS CORTISOL is characterized by various metabolic disturbances, including the presence of fasting hyperglycemia and impaired glucose tolerance $(21,23,34,37)$. Furthermore, excess cortisol induces hepatic and extrahepatic insulin resistance. However, the mechanism(s) responsible for cortisolinduced insulin resistance are poorly understood $(28,41)$.

Under conditions of daily living, after ingestion of a carbohydrate meal, glucose and insulin rise and fall in a tightly coordinated manner. The rise in plasma glucose concentration stimulates insulin secretion, which results in suppression of glucose release and stimulation of glucose uptake $(12,31)$. However, glucose per se also plays a pivotal role in the regulation of postprandial glucose metabolism. Hyperglycemia suppresses glucose release and stimulates glucose disposal through a mechanism referred to as glucose effectiveness (7). Thus, in addition to pancreatic $\beta$-cell function and insulin action, postprandial glucose tolerance depends on the ability of glucose per se to stimulate its own metabolism. Whereas several studies have determined the effects of cortisol on insulin action, the impact of excess cortisol on gluconeogenesis and glucose effectiveness, both of which contribute to hyperglycemia in insulin-resistant states such as diabetes mellitus, has to our knowledge not yet been examined.

Glucose effectiveness is traditionally assessed by use of the minimal model, which is based on the frequently sampled intravenous glucose tolerance (FSIGT) test. However, whereas a close correlation has been established between the glucose clamp-derived estimate of insulin action and the minimal model-derived insulin sensitivity index, the ability of the minimal model to accurately estimate glucose effectiveness is less certain $(15,40)$. The present study, therefore, sought to determine the effects of cortisol on glucose effectiveness by using a minimal model-independent approach (5). Furthermore, to determine whether altered glucose effectiveness is due to an impaired ability of glucose to suppress glucose production and/or the ability of glucose to stimulate its own uptake, rates

The costs of publication of this article were defrayed in part by the payment of page charges. The article must therefore be hereby marked "advertisement" in accordance with 18 U.S.C. Section 1734 solely to indicate this fact. 
of glucose production and utilization were determined using the tracer-dependent glucose infusion ("hot-GINF") method. Tracer-dependent indexes of glucose effectiveness, i.e., $\mathrm{GE}_{\mathrm{b}}^{*}$ and $\mathrm{GE}_{\text {liver, }}$, were calculated by use of a model-independent approach. The effects of cortisol on postabsorptive gluconeogenesis were assessed by combining the isotope dilution method with the ${ }^{2} \mathrm{H}_{2} \mathrm{O}$ technique (25).

\section{MATERIALS AND METHODS}

Subjects. After approval from the Ethics Committee, County of Aarhus, eight healthy subjects ( 5 males and 3 females) with a mean age of $26 \mathrm{yr}(21-29 \mathrm{yr}$ ), lean body mass of $62.4 \pm 4.5 \mathrm{~kg}$, and a body mass index of $24.4 \pm 0.8 \mathrm{~kg} / \mathrm{m}^{2}$, and without any family history of diabetes gave written consent to participate in the study. Lean body weight was measured using bioelectric impedance (Animeter; HTSEngineering APS, Odense, Denmark). All participants were Caucasian. Female volunteers were studied in the middle of the menstrual cycle. No recruited subjects were taking any medication. At least 3 days before study, subjects were instructed not to engage in vigorous exercise. During the study period, volunteers were encouraged to refrain from changes in eating behavior and exercise activities.

Experimental design. Subjects were admitted to the clinical research center at 2130 on the evening before the study (Fig. 1). Study subjects were instructed to eat their last meal at 1800. On the subject's admission, an 18-gauge cannula was inserted into a forearm vein of each arm. One cannula was used for venous blood sampling and the other for hormone and tracer infusion.

Each subject was studied on two occasions in random order separated by $3 \mathrm{mo}$. This time interval was chosen to ensure negligible amounts of deuterium-labeled glycogen on the second study day. On one occasion, an infusion of hydrocortisone $\left(2.0 \mu \mathrm{g} \cdot \mathrm{kg}^{-1} \cdot \mathrm{min}^{-1}\right.$; Solu-Cortef, Pharmacia \& Upjohn) dissolved in saline was started at 2200 and maintained at that rate until 1630 (time 300) of the next day. On the second occasion, saline was infused at a rate of $1.8 \mathrm{l} / \mathrm{h}$. At 2200, 2400, and 0200, the subjects drank $1.7 \mathrm{ml}$ of ${ }^{2} \mathrm{H}_{2} \mathrm{O}(99.9 \% \mathrm{H}$; Cambridge Isotope Laboratories, Andover, MA) per kilogram body water. Body water was calculated to be $50 \%$ of total body weight in women and $60 \%$ in men. Water ingested ad libitum thereafter was enriched to be $0.5 \%{ }^{2} \mathrm{H}_{2} \mathrm{O}$ to maintain isotopic steady state. At 0500 (time -390$)$, a primed continuous infusion of $\left[3-{ }^{3} \mathrm{H}\right]$ glucose $(17 \mu \mathrm{Ci}$ prime, $0.17 \mu \mathrm{Ci} / \mathrm{min}$ continuous) was started and maintained throughout the experiment. At 0630, the hand used for blood sampling was placed in a heated Plexiglas box and maintained at a temperature of $\sim 55^{\circ} \mathrm{C}$ throughout the study to allow sampling of arterialized venous blood. Postabsorptive glucose release (EGR) and gluconeogenesis were determined from 0700 to 0730 .

At 0730 (time -240), an intravenous infusion containing somatostatin $\left(60 \mathrm{ng} \cdot \mathrm{kg}^{-1} \cdot \mathrm{min}^{-1}\right.$; Ferring, Kiel, Germany), glucagon (0.65 $\mathrm{ng} \cdot \mathrm{kg}^{-1} \cdot \mathrm{min}^{-1}$; Novo Nordisk, Bagsværd, Denmark), and growth hormone $\left(2 \mathrm{ng} \cdot \mathrm{kg}^{-1} \cdot \mathrm{min}^{-1}\right.$; Novo Nordisk) was begun in all subjects. An infusion of insulin (Insulin Actrapid; Novo Nordisk) was also started at rates of $0.15 \mathrm{mU} \cdot \mathrm{kg}^{-1} \cdot \mathrm{min}^{-1}$ on the saline day and 0.25 $\mathrm{mU} \cdot \mathrm{kg}^{-1} \cdot \mathrm{min}^{-1}$ on the cortisol day. Plasma glucose concentration was measured at 15 -min intervals with a glucose oxidase method (Beckman Instruments, Brea, CA), and the insulin infusion rate was adjusted to maintain glucose at $\sim 5 \mathrm{mmol} / \mathrm{l}$. The last adjustment of this "basal" insulin infusion was made $\geq 30 \mathrm{~min}$ before start of the prandial glucose infusion and was maintained at that rate for the remainder of the study.

At 1130 (time 0), a 5-h preprogrammed variable glucose infusion was started with an infusion pump (model PhD 2000; Harvard Apparatus, South Natick, MA) driven by a PC 2/30 265 computer (IBM, Rochester, MN). Glucose was infused in a manner mimicking the systemic rate of appearance of glucose that occurs after ingestion of $50 \mathrm{~g}$ of glucose (1). The pattern and amount of glucose infused normalized to lean body mass were equal on the two study days.

In an effort to maintain specific activities constant, the rate of basal $\left[3-{ }^{3} \mathrm{H}\right]$ glucose was adjusted $(-390-0 \mathrm{~min}, 100 \%$; 0-30 $\mathrm{min}, 70 \%$; 30-60 min, 46\%; 60-120 min, 55\%; 120-150 min, 53\%; 150-300 $\min , 61 \%$ ) according to the anticipated suppression of EGR during the prandial glucose infusion. Furthermore, all glucose infused contained $\left[3-{ }^{3} \mathrm{H}\right]$ glucose. Hence, glucose specific activities remained constant on the two study days.

To avoid the confounding effects of counterregulation during hypoglycemia, the experiments were terminated when plasma glucose concentrations fell below $2.7 \mathrm{mmol} / \mathrm{l}(50 \mathrm{mg} / \mathrm{dl})$.

Analytical techniques. Arterialized plasma glucose was measured in duplicate immediately after sampling. Samples for hormone analysis were placed on ice, centrifuged at $4^{\circ} \mathrm{C}$, separated, and stored at $-20^{\circ} \mathrm{C}$ until assay. Serum insulin was determined by two-site enzyme-linked immunosorbent assay (2). Plasma glucagon and Cpeptide concentrations were measured by radioimmunoassay. Serum free fatty acids (FFA) were measured enzymatically using a Wako NEFA (nonesterified fatty acid) Test Kit (Wako Chemicals, Neuss, Germany).

The measurement of deuterium enrichment on carbons 2 and 5 in glucose was performed as previously described (25). Briefly, $15 \mathrm{ml}$ of

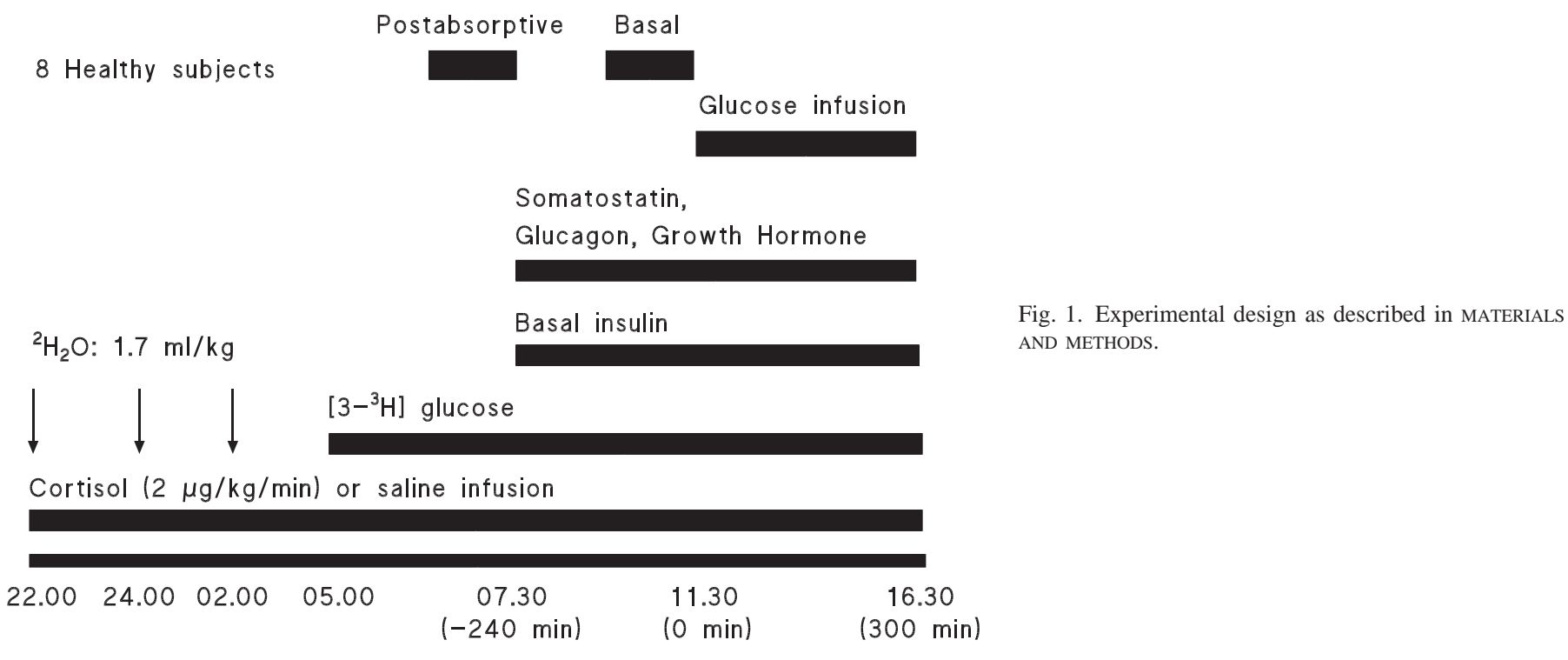

AJP-Endocrinol Metab $・$ VOL $286 \cdot$ JANUARY $2004 \cdot$ www.ajpendo.org 
blood were diluted with $30 \mathrm{ml}$ of demineralized water and deproteinized using $15 \mathrm{ml}$ of $0.3 \mathrm{~N} \mathrm{ZnSO}_{4}$ and $15 \mathrm{ml}$ of $0.3 \mathrm{~N} \mathrm{Ba}(\mathrm{OH})_{2}$. The samples were centrifuged at 2,000 rpm for $15 \mathrm{~min}$, and the pellet was diluted in $15 \mathrm{ml}$ of demineralized water to wash out the remaining glucose. Glucose was isolated by successive ion-exchange chromatography and high-performance liquid chromatography. For determination of deuterium enrichment on C5, glucose was first converted to xylose, and the C5 of glucose with its hydrogens was cleaved by periodate oxidation to formaldehyde, which was condensed with ammonium hydroxide to form hexamethylenetetramine (HMT). The ${ }^{2} \mathrm{H}$ bound to $\mathrm{C} 2$ of glucose was isolated after conversion of glucose to ribitol-5-phosphate and arabitol-5-phosphate and treatment to form HMT. HMT was analyzed on a Hewlett-Packard mass spectrometry system. Standard solutions of glucose of known enrichment were run along with the unknown samples to calibrate for instrument variations.

Calculation of glucose turnover. Glucose turnover, i.e., EGR and glucose utilization, was calculated using Steele's equations for nonsteady state (45). The pool correction factor and the glucose volume of distribution were assumed to be 0.65 and $260 \mathrm{ml} / \mathrm{kg}$, respectively. Glucose specific activity, calculated as the ratio between tracer (dpm/ $\mathrm{ml}$ ) and plasma glucose concentration, was smoothed from 0 to 300 min by use of the OOPSEG program of Bradley et al. (8). Glucose production and utilization at time 0 were calculated using the average specific activity from -30 to $0 \mathrm{~min}$. Glucose clearance was calculated as the ratio between glucose utilization $\left(R_{d}\right)$ and the corresponding plasma glucose concentration. The fractional contribution of gluconeogenesis to glucose release was determined as the ratio of deuterium bound to carbon 5 in glucose to that bound to carbon 2 (25). A quantitative estimate of postabsorptive gluconeogenesis was calculated by multiplying the mean glucose release from 0700 to 0730 by the mean of the fractional contribution of gluconeogenesis to EGR from 0630 to 0730 .

Assessment of glucose effectiveness. The calculation of net glucose effectiveness $\left(\mathrm{GE}_{\mathrm{b}}, \mathrm{ml} \cdot \mathrm{kg}^{-1} \cdot \mathrm{min}^{-1}\right)$, i.e., the ability of glucose to suppress glucose release and stimulate glucose utilization, has been described elsewhere $(5,32)$. Net glucose effectiveness at basal insulin concentration was calculated as the ratio between the area under the curve (AUC) of the exogenous glucose infusion rate (GIR) and the AUC of the glucose concentration above basal $(\Delta \mathrm{G})$

$$
\mathrm{GE}_{\mathrm{b}}=\frac{\operatorname{AUC}[\mathrm{GIR}(t)]}{\operatorname{AUC}[\Delta \mathrm{G}(t)]}
$$

Because equal amounts of glucose were infused in each subject on the two study days, the excursion of glucose concentration above basal is inversely related to net glucose effectiveness. The greater the glycemic excursion, the lower the net glucose effectiveness $\left(\mathrm{GE}_{\mathrm{b}}\right)$.

To determine the effects of glucose on glucose production and utilization, hot (tracer-determined) indexes of glucose effectiveness, i.e., $\mathrm{GE}_{\mathrm{b}}^{*}$ and $\mathrm{GE}_{\text {liver, }}$, were calculated from glucose and $\left[3-{ }^{3} \mathrm{H}\right]$ glucose concentrations (5). Whereas $\mathrm{GE}_{\mathrm{b}}^{*}\left(\mathrm{ml} \cdot \mathrm{kg}^{-1} \cdot \mathrm{min}^{-1}\right)$ determines the ability of glucose at basal insulin to facilitate its own disposal, $\mathrm{GE}_{\text {liver }}$ $\left(\mathrm{ml} \cdot \mathrm{kg}^{-1} \cdot \mathrm{min}^{-1}\right)$ determines the effect of glucose to suppress its own production. These estimates are equivalent to those derived using the glucose clamp technique. The effect of glucose on glucose disposal was calculated as follows

$$
\mathrm{GE}_{\mathrm{b}}^{*}=\frac{\left\{\operatorname{AUC}\left[\Delta \mathrm{GIR}^{*}(t)\right]-\mathrm{PCR}_{\mathrm{b}} \mathrm{G}_{\mathrm{b}} \mathrm{AUC}[\Delta \mathrm{SA}(t)]\right\}}{\left\{\mathrm{AUC}\left[\Delta \mathrm{G}^{*}(t)\right]-\mathrm{G}_{\mathrm{b}} \mathrm{AUC}[\Delta \mathrm{SA}(t)]\right\}}
$$

where $\Delta \mathrm{GIR}^{*}$ is the tracer infusion rate above basal, $\mathrm{G}^{*}$ is the tracer concentration, $\mathrm{SA}$ is the tracer specific activity, and $\mathrm{PCR}_{\mathrm{b}}$ is the basal plasma glucose clearance rate.

The effect of glucose on glucose production $\left(\mathrm{GE}_{\text {liver }}\right.$, $\mathrm{ml} \cdot \mathrm{kg}^{-1} \cdot \mathrm{min}^{-1}$ ) was calculated by dividing the area below basal of EGR by the area above basal of glucose concentration. Since $\mathrm{GE}_{\mathrm{b}}$ constitutes the effects of glucose both to suppress its own production and to facilitate its own disposal, $\mathrm{GE}_{\mathrm{liver}}$ can also be calculated by subtracting $\mathrm{GE}_{\mathrm{b}}^{*}$ from $\mathrm{GE}_{\mathrm{b}}$.

Plasma glucose clearance rate (PCR) and GE* are related according to the following equation

$$
\operatorname{PCR}(t)=\mathrm{GE}_{\mathrm{b}}^{*}+\mathrm{R}_{\mathrm{d}, 0} / \mathrm{G}(t)
$$

where $R_{d, 0}$ equals the hypothetical rate of glucose uptake at zero glucose concentration.

Assessment of basal insulin sensitivity. Insulin action was determined from postabsorptive glucose and insulin concentrations with the homeostatic model assessment analysis for insulin sensitivity (HOMA), as proposed by Turner and colleagues [Matthews et al. (26) and Turner et al. (46)]. To account for differences in FFA concentrations, insulin sensitivity was also calculated on the basis of the recently revised QUICKI method, as suggested by Perseghin et al. (38).

Statistical analysis. Data in the text and Figs. 1-9 are expressed as means \pm SE. All rates are expressed per kilogram of lean body weight. Integrated responses and responses above basal were calculated using the trapezoidal rule. Integrated response was defined as total area above zero during saline or steroid infusion. Postabsorptive measures were obtained from 0700 to 0730 ( -270 to $-240 \mathrm{~min}$ ) (Fig. 1). Basal measures, i.e., those obtained in the presence of basal insulin concentrations, were defined as the means of values from 1100 to $1130(-30-0 \mathrm{~min})$. A paired Student's $t$-test was used to test for differences during saline or steroid infusion. The Wilcoxon rank sum test was used for data not fulfilling the criteria for normal distribution (27). A $P$ value $<0.05$ was considered statistically significant.

\section{RESULTS}

Postabsorptive glucose, FFA, and hormone concentrations. Postabsorptive cortisol $(1,243 \pm 133$ vs. $386 \pm 50 \mathrm{nmol} / \mathrm{l}, P<$ $0.01)$, glucose (6.72 \pm 0.20 vs. $4.91 \pm 0.13 \mathrm{mmol} / \mathrm{l}, P<0.01)$, insulin (52 \pm 5 vs. $33 \pm 2$ pmol/1, $P<0.05)$, and C-peptide concentrations $(594 \pm 55$ vs. $476 \pm 34 \mathrm{pmol} / \mathrm{l}, P<0.05)$ were greater after overnight cortisol infusion than during saline infusion (Fig. 2). During the night, circulating FFA concentrations increased on both study days (Fig. 3). However, FFA concentrations were higher during cortisol than during saline infusion $(0.71 \pm 0.07$ vs. $0.47 \pm 0.06 \mathrm{mmol} / \mathrm{l}, P<0.01)$. Postabsorptive plasma glucagon concentrations did not differ on the two study days $(51 \pm 8$ vs. $48 \pm 9 \mathrm{pg} / \mathrm{ml}, P=0.82)$.

Postabsorptive EGR, gluconeogenesis, and insulin sensitivity. Despite higher glucose and insulin concentrations during cortisol than during saline infusion, postabsorptive glucose production $\left(12.4 \pm 0.5\right.$ vs. $11.9 \pm 0.7 \mu \mathrm{mol} \cdot \mathrm{kg}^{-1} \cdot \mathrm{min}^{-1}, P=$ $0.64)$ and gluconeogenesis (8.1 \pm 0.6 vs. $7.1 \pm 0.5$ $\left.\mu \mathrm{mol} \cdot \mathrm{kg}^{-1} \cdot \mathrm{min}^{-1}, P=0.33\right)$ did not differ on the two study days (Fig. 4). Gluconeogenesis accounted for $62.9 \pm 4.6$ and $59.8 \pm 3.9 \%$ of total glucose release during cortisol and saline infusion, respectively. Insulin sensitivity, determined by both the HOMA analysis $(2.58 \pm 0.30$ vs. $1.19 \pm 0.14 ; P<0.01)$ and the revised QUICKI method $(0.35 \pm 0.01$ vs. $0.43 \pm 0.01$; $P<0.01$ ), was markedly lower during cortisol than during saline infusion, implying steroid-induced insulin resistance.

Although postabsorptive glucose concentrations were higher during steroid infusion, glucose uptake did not differ significantly on the two study days (12.4 \pm 0.5 vs. $11.9 \pm 0.7$ $\left.\mu \mathrm{mol} \cdot \mathrm{kg}^{-1} \cdot \mathrm{min}^{-1} ; P=0.64\right)$. Consequently, glucose clearance was lower during steroid than during saline infusion $\left(1.89 \pm 0.06\right.$ vs. $\left.2.42 \pm 0.18 \mathrm{ml} \cdot \mathrm{kg}^{-1} \cdot \mathrm{min}^{-1} ; P<0.05\right)$. 
A
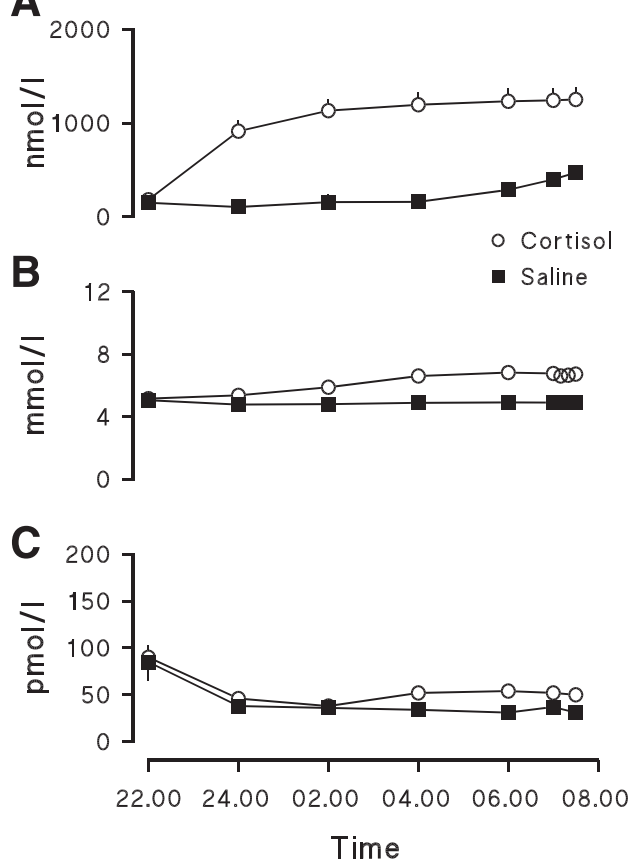

Fig. 2. Nocturnal plasma cortisol $(A)$, glucose $(B)$, and insulin $(C)$ concentrations during cortisol $(O)$ or saline $(\mathbf{\square})$ infusion.

Substrate and hormone concentrations during prandial glucose infusion. "Basal" insulin infusion rate, defined as the infusion rate required to maintain glucose concentration at $\sim 5$ $\mathrm{mM}\left(0.27 \pm 0.02\right.$ vs. $\left.0.16 \pm 0.01 \mathrm{mU} \cdot \mathrm{kg}^{-1} \cdot \mathrm{min}^{-1}, P<0.01\right)$, and the corresponding basal insulin concentrations $(88 \pm 5 \mathrm{vs}$. $65 \pm 3 \mathrm{pmol} / \mathrm{l}, P<0.05$ ) were higher during cortisol than during saline infusion, indicating the presence of steroidinduced insulin resistance (Fig. 5). Basal C-peptide (31 \pm 5 vs.

A

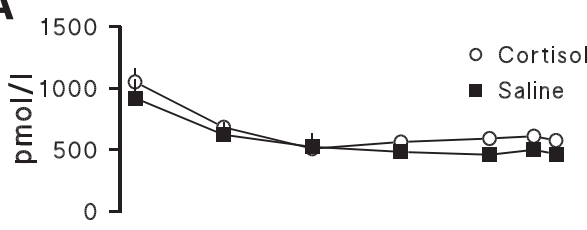

B
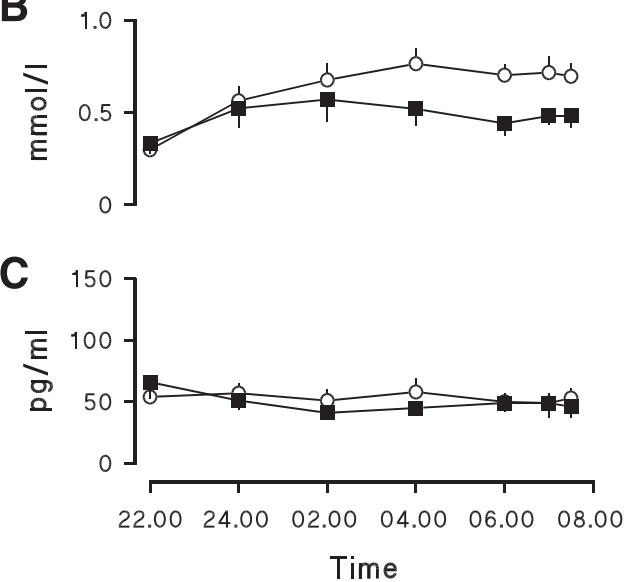

Fig. 3. Nocturnal C-peptide $(A)$, free fatty acid (FFA, $B$ ), and glucagon $(C)$ concentrations during cortisol $(O)$ or saline $(\square)$ infusion.

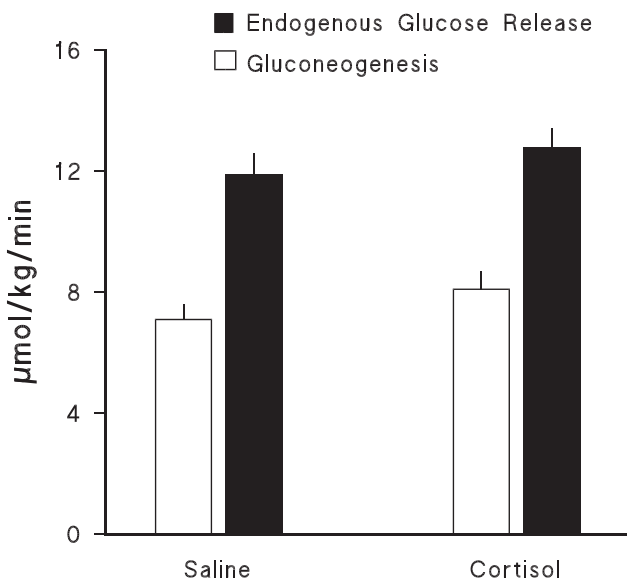

Fig. 4. Postabsorptive rates of endogenous glucose release and gluconeogenesis during nocturnal cortisol or saline infusion. Gluconeogenesis was calculated by multiplying the mean ratio of deuterium enrichment at carbon 5 to that at carbon 2 in glucose by the mean rate of fasting endogenous glucose release from -30 to $0 \mathrm{~min}$.

$28 \pm 8 \mathrm{pmol} / \mathrm{l}, P=0.77)$ and glucagon $(65 \pm 7$ vs. $66 \pm 8$ $\mathrm{pg} / \mathrm{ml}, P=0.85)$ concentrations did not differ on the two study days (Fig. 6). Basal FFA concentrations $(0.34 \pm 0.04$ vs. $0.17 \pm 0.02 \mathrm{mmol} / \mathrm{l}, P<0.01)$ were higher during cortisol than during saline infusion.

In the presence of prandial glucose infusion, basal insulin concentrations remained constant and higher during cortisol than during saline infusion. Glucose infusion did not alter FFA or glucagon concentrations. During somatostatin infusion, Cpeptide concentrations were completely suppressed on both study days, implying suppressed endogenous insulin secretion during the prandial glucose infusion.
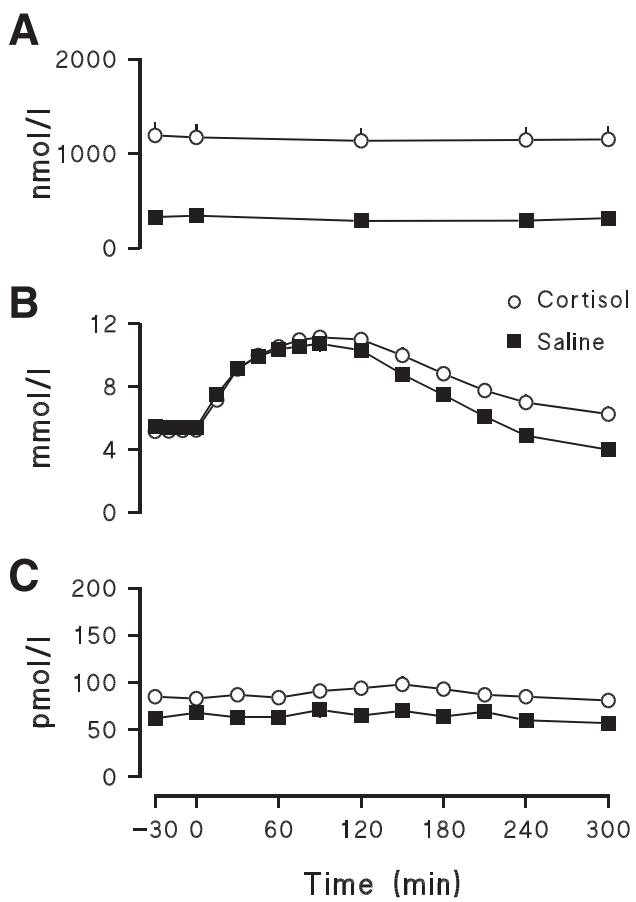

Fig. 5. Plasma cortisol $(A)$, glucose $(B)$, and serum insulin $(C)$ concentrations during prandial glucose infusion in the presence of cortisol $(O)$ or saline ( $(\mathbf{)}$ infusion. The glucose infusion was started at $0 \mathrm{~min}$. 
A

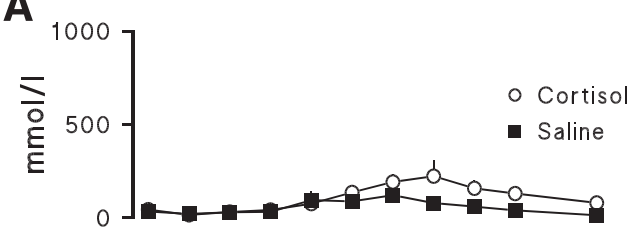

B
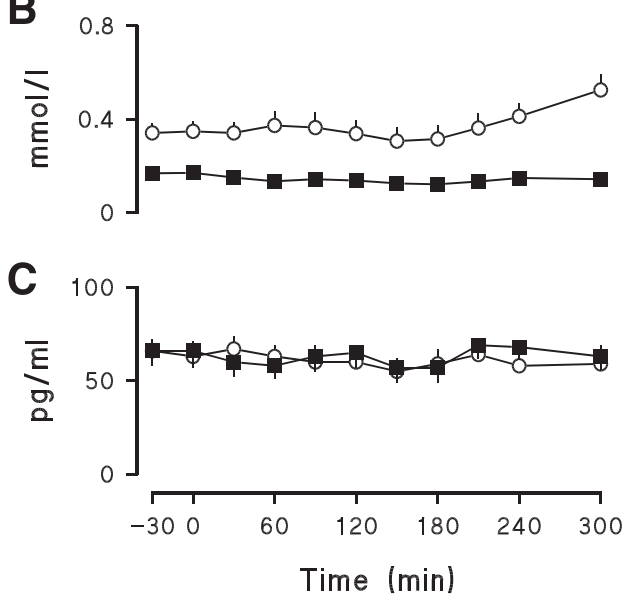

Fig. 6. C-peptide $(A)$, FFA $(B)$, and plasma glucagon $(C)$ concentrations during prandial glucose infusion in the presence of cortisol $(\bigcirc)$ or saline $(\boldsymbol{\square})$ infusion. The glucose infusion was started at $0 \mathrm{~min}$.

Estimate of glucose effectiveness during the prandial glucose infusion. Before the prandial glucose infusion, glucose concentrations ( $5.20 \pm 0.12$ vs. $5.44 \pm 0.13 \mathrm{mmol} / \mathrm{l}, P=0.27)$ were comparable and constant on both study days. In the presence of constant basal insulin concentrations, the glycemic excursion during glucose infusion was greater during cortisol than during saline infusion $(1,082 \pm 108$ vs. $751 \pm 72$ $\left.\mathrm{mmol} \cdot \mathrm{l}^{-1} \cdot 5 \mathrm{~h}^{-1}, P<0.05\right)$. Consequently, net glucose effectiveness $\left(4.42 \pm 0.52\right.$ vs. $6.65 \pm 0.83 \mathrm{ml} \cdot \mathrm{kg}^{-1} \cdot \mathrm{min}^{-1}, P<$ 0.05 ) was impaired during cortisol infusion (Fig. 7).

Net glucose effectiveness, $\mathrm{GE}_{\mathrm{b}}$, is a composite measure of the ability of glucose to promote its own uptake (GE*) and to suppress its own production $\left(\mathrm{GE}_{\text {liver }}\right)$. Because of the infusion of a glucose tracer, the present design also allows a calculation of these hot indexes of glucose effectiveness. Whereas $\mathrm{GE}_{\text {liver }}$

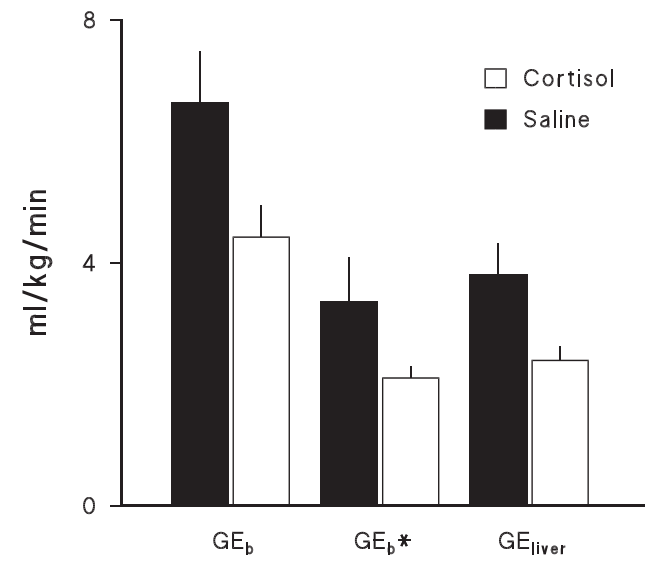

Fig. 7. Estimates of glucose effectiveness during basal insulin concentrations. Net glucose effectiveness $\left(\mathrm{GE}_{\mathrm{b}}\right)$ constitutes the combined effects of glucose to stimulate its own uptake $\left(\mathrm{GE}_{\mathrm{b}}^{*}\right)$ and suppress its own production $\left(\mathrm{GE}_{\text {liver }}\right)$. values were higher during saline than during steroid infusion $\left(3.82 \pm 0.51\right.$ vs. $\left.2.39 \pm 0.24 \mathrm{ml} \cdot \mathrm{kg}^{-1} \cdot \mathrm{min}^{-1}, P<0.05\right), \mathrm{GE}_{\mathrm{b}}^{*}$ (although higher during saline than during steroid infusion in 6 of 8 subjects) did not differ significantly on the two study days ( $3.37 \pm 0.72$ vs. $\left.2.10 \pm 0.19 \mathrm{ml} \cdot \mathrm{kg}^{-1} \cdot \mathrm{min}^{-1}, P=0.15\right)$.

Plasma glucose clearance rate (PCR) is related to $\mathrm{GE}_{\mathrm{b}}^{*}, \mathrm{R}_{\mathrm{d}, 0}$, and glucose concentration as specified in $E q$. 3. $\mathrm{R}_{\mathrm{d}, 0}$ was calculated in each subject by substituting in Eq. 3 the pretest values of PCR and glucose concentration. In the present experiments, $\mathrm{R}_{\mathrm{d}, 0}$ did not differ on the two study days $\left(-4.08 \pm 3.53\right.$ vs. $\left.1.37 \pm 1.14 \mu \mathrm{mol} \cdot \mathrm{kg}^{-1} \cdot \mathrm{min}^{-1} ; P=0.24\right)$. During the prandial glucose infusion, PCR changed as a consequence of the change in glucose concentration. Mean rates of PCR during glucose infusion were lower during cortisol than during saline infusion $(2.23 \pm 0.08$ vs. $2.77 \pm 0.20$ $\left.\mathrm{ml} \cdot \mathrm{kg}^{-1} \cdot \mathrm{min}^{-1} ; P<0.05\right)$.

Glucose turnover during prandial glucose infusion. To determine the effects of glucose on glucose kinetics, rates of EGR and glucose disappearance were measured during the prandial glucose infusion (Figs. 8 and 9). In the presence of basal insulin concentrations, postabsorptive EGR values (14.2 \pm 0.6 vs. $\left.12.3 \pm 0.4 \mu \mathrm{mol} \cdot \mathrm{kg}^{-1} \cdot \mathrm{min}^{-1} ; P<0.05\right)$ were higher during saline than during cortisol infusion. During the prandial glucose infusion, EGR rates were suppressed promptly and equally on the two study days $(1,570 \pm 285$ vs. $1,211 \pm 162$ $\mu \mathrm{mol} / \mathrm{kg} ; P=0.26$ ). Because equal rates of glucose production were obtained despite higher glucose concentrations during steroid infusion, these results imply a defect in the ability of glucose to suppress EGR during excess hydrocortisone concentrations.

In the presence of basal insulin concentrations, basal glucose rates of disappearance were higher during saline than during cortisol infusion $\left(14.3 \pm 0.6\right.$ vs. $12.3 \pm 0.4 \mu \mathrm{mol} \cdot \mathrm{kg}^{-1} \cdot \mathrm{min}^{-1}$;
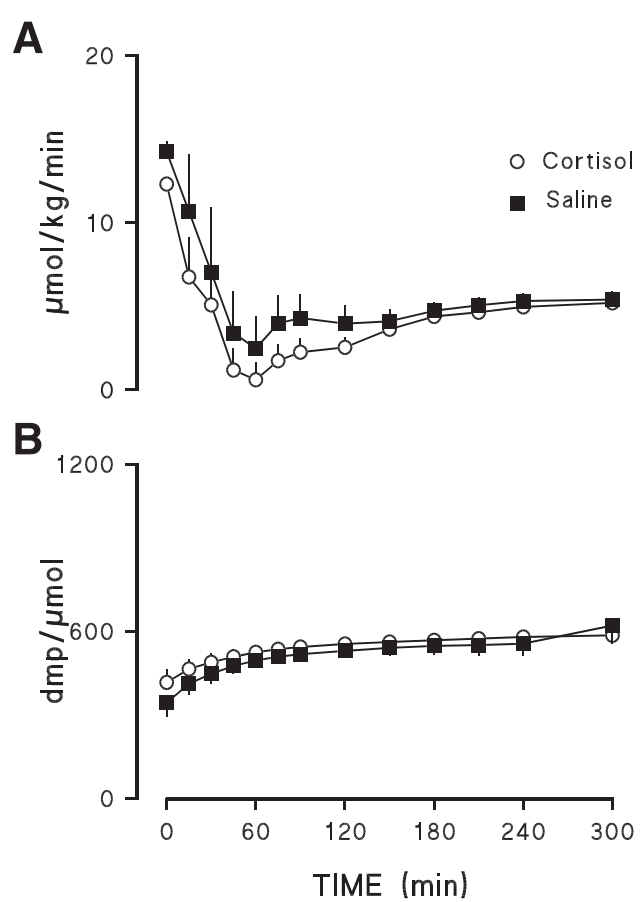

Fig. 8. Endogenous glucose release $(A)$ and $\left[3-{ }^{3} \mathrm{H}\right]$ glucose specific activity $(B)$ during prandial glucose infusion in the presence of cortisol $(\bigcirc)$ or saline $(\mathbf{\square})$ infusion. The glucose infusion was started at $0 \mathrm{~min}$. 
A

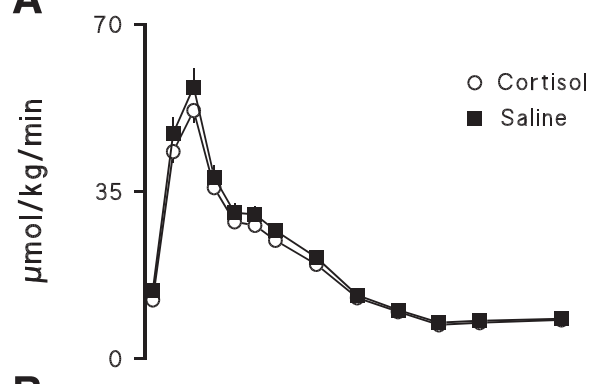

B

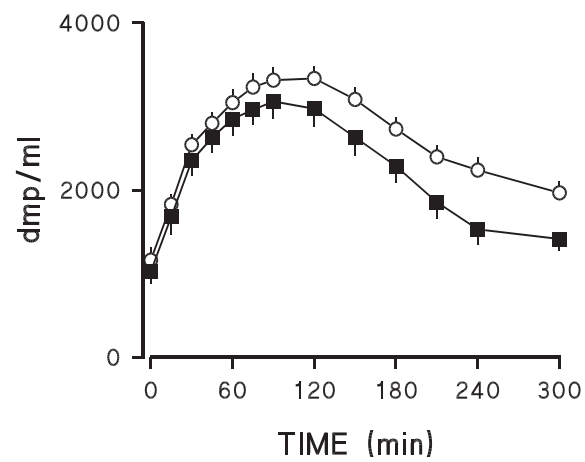

Fig. 9. Rate of disappearance $(A)$ and $\left[3-{ }^{3} \mathrm{H}\right]$ glucose concentrations $(B)$ during prandial glucose infusion in the presence of cortisol (O) or saline ( $\mathbf{\square})$ infusion. The glucose infusion was started at $0 \mathrm{~min}$.

$P<0.05)$. During the prandial glucose infusion, glucose disappearance did not differ on the two study days $(5,869 \pm$ 281 vs. $5,532 \pm 171 \mathrm{mmol} / \mathrm{kg} ; P=0.31)$. Consequently, in the presence of excess cortisol, rates of disappearance were inappropriate for the higher glucose concentrations, indicating impaired plasma glucose clearance $(2.77 \pm 0.20$ vs. $2.23 \pm$ $\left.0.08 \mathrm{ml} \cdot \mathrm{kg}^{-1} \cdot \mathrm{min}^{-1} ; P<0.05\right)$.

The same tracer infusion profile was applied during saline and steroid infusions. Therefore, identical amounts of $\left[3-{ }^{3} \mathrm{H}\right]$ glucose were infused in all subjects. Consequently, the excursion of $\left[3-{ }^{3} \mathrm{H}\right]$ glucose concentration during the prandial glucose infusion yields a model-independent assessment of glucose uptake. In the present experiments, $\left[3-{ }^{3} \mathrm{H}\right]$ glucose concentrations were higher during steroid than during saline infusion $\left(650,515 \pm 62,403\right.$ vs. $791,385 \pm 38,411 \mathrm{dpm} \cdot \mathrm{ml}^{-1} \cdot 5$ $\left.\mathrm{h}^{-1} ; P<0.05\right)$. This difference in tracer concentration implies a lower rate of glucose disappearance and confirms the presence of an impairment of glucose clearance during hypercortisolemia.

\section{DISCUSSION}

Previous studies have demonstrated that excess cortisol induces hepatic and extrahepatic insulin resistance $(3,18,20$, $28,41,42,48)$. Metabolic effects may be induced by the normal circadian variation in cortisol secretion $(10,11)$. Besides coincident disturbances in protein and lipid metabolism, hypercortisolemia is also characterized by hyperinsulinemia and hyperglycemia $(13,21,23,34,37,43)$. The mechanism(s) by which glucocorticoids induce alterations in glucose metabolism are, however, sparsely elucidated. Glucocorticoids are reported to decrease glucose transport (36), and conflicting results are reported on the effects of glucocorticoids on insulin binding $(6,14,22)$.
Under conditions of daily living, glucose and insulin concentrations rise and fall in a tightly coordinated manner. An increase in either glucose or insulin will suppress glucose production and stimulate glucose uptake. The concurrent rise in concentration of both glucose and insulin will exert a greater response than a rise in either alone (31). Previous studies have established that excess cortisol, measured either during clamp conditions or in the presence of physiological changes in insulin concentrations, alters insulin action. However, the effects of glucocorticoids on glucose effectiveness, i.e., the ability of glucose to regulate its own metabolism, have to our knowledge never been examined. The present study was designed to determine the effects of hypercortisolemia on postabsorptive and postprandial glucose metabolism. Hydrocortisone was infused at a rate known to induce hepatic and extrahepatic insulin resistance (41). During steroid infusion, cortisol concentrations increased threefold from baseline to $\sim 1,200 \mathrm{nmol} / \mathrm{l}$. This concentration is equivalent to the adrenal response seen after severe trauma or surgical stress $(9,30$, $35,47)$.

Despite higher fasting insulin concentrations, both glucose and FFA concentrations were higher during steroid than during saline infusion. Although insulin action was not directly measured, both HOMA analysis and the revised QUICKI method suggest that insulin action was impaired, implying that the presence of insulin resistance was partially compensated by an increase in insulin secretion. Fasting EGR, gluconeogenesis, and, by implication, fasting glycogenolysis were unaltered during hydrocortisone infusion; that is, net glycogenolysis to the extent that there is glycogen cycling, with perhaps more cycling on hydrocortisone administration (24). Because glucose and insulin concentrations were both higher during hydrocortisone than during saline infusion, the present data suggest an impaired ability of insulin and glucose to suppress postabsorptive glucose production during excess cortisol concentrations.

The effects of glucocorticoids on hepatic glucose metabolism have been studied in both in vivo and in vitro experiments. Gluconeogenic conversion of alanine to glucose has been demonstrated to be increased during acute rises in plasma cortisol (19). Furthermore, phosphoenolpyruvate carboxykinase (PEPCK) activity is increased by glucocorticoids, consistent with an increase in gluconeogenesis during hypercortisolemia (16). As pointed out by Sasaki et al. (44), dexamethasoneinduced increase of PEPCK gene transcription is either blunted or totally inhibited by elevated insulin, suggesting that insulin is a dominant hormone in the regulation of gluconeogenesis (44). Therefore, in the present experiments, the observation of unaltered rates of gluconeogenesis and glucose production during hypercortisolemia may be attributed to the inhibition of insulin on PEP kinase transcription. This conclusion is supported by studies in overnight-fasted dogs in which a fivefold elevation in plasma cortisol resulted in minimally elevated rates of gluconeogenesis despite increased plasma insulin and glucose concentrations (20).

Although several studies have determined the effects of hydrocortisone on insulin action $(3,28,41,48)$, the effects of glucocorticoids on glucose effectiveness are unknown. The classic minimal model analysis based on the FSIGT was originally designed to estimate insulin action. The model also allows an estimate of glucose effectiveness, but the accuracy of 
that estimate has been challenged. It has been demonstrated that the cold minimal model in its original form provides an overestimate of glucose effectiveness when assessed in the presence of changing glucose concentrations (15). For that reason, we chose in the present experiments to assess glucose effectiveness by use of a minimal model-independent approach in which insulin was maintained at basal concentrations and the glycemic excursion was measured during a standardized glucose infusion (5).

We have previously demonstrated that the estimate of glucose effectiveness is sensitive to even subtle changes in insulin concentrations (32). This is the case because EGR is inhibited and glucose uptake is stimulated by insulin. Because cortisol induces hepatic and extrahepatic insulin resistance to obtain the same biological effect, higher insulin concentrations were required during hypercortisolemia than during saline infusion. To ensure that the response to exogenous glucose infusion was assessed in the presence of biologically equivalent amounts of insulin, the appropriate basal insulin concentration was individually determined on each occasion in each study subject. We defined basal as the insulin concentration necessary to maintain the subject's glucose concentration constant at 5.5 $\mathrm{mmol} / \mathrm{l}$. Inspection of Fig. 5 indicates that this goal was clearly achieved during both saline and steroid infusions.

As depicted in Fig. 5, the basal insulin infusion rate ( 0.27 vs. $\left.0.16 \mathrm{mU} \cdot \mathrm{kg} \mathrm{TBW}{ }^{-1} \cdot \mathrm{min}^{-1} ; P<0.01\right)$ and the corresponding insulin concentrations ( $88 \pm 5$ vs. $65 \pm 3 \mathrm{pmol} / \mathrm{l} ; P<0.05$ ) were higher during cortisol than during saline infusion, indicating the presence of steroid-induced insulin resistance. Moreover, basal insulin concentrations were maintained constant from -30 until the end of the prandial glucose infusion. Because each subject received the same glucose infusion profile, the higher glycemic excursion, measured either in terms of peak glucose concentrations or as integrated area above baseline, indicates a decrease in net glucose effectiveness during hypercortisolemia (Fig. 5).

The higher glucose concentrations during steroid infusion could have been due to inappropriately high rates of EGR, inappropriately low rates of glucose utilization, or a combination of both. Thus, to gain insight into the mechanism by which glucose effectiveness is impaired, glucose production and rates of glucose utilization were determined using the hot-GINF method. Moreover, model-independent estimates of hot indexes of glucose effectiveness were calculated on the basis of glucose and $\left[3-{ }^{3} \mathrm{H}\right]$ glucose concentrations.

During the prandial glucose infusion, EGR decreased promptly and equally on the two study days. However, these rates of glucose production were obtained in the presence of higher glucose concentrations during steroid infusion. Inspection of Fig. 8 suggests that, whereas suppression of EGR appeared unaltered during the early part of the prandial glucose infusion, the rate of suppression was inadequate from $150 \mathrm{~min}$ and onward, implying an abnormal suppression of EGR by glucose in the presence of hypercortisolemia. Moreover, $\mathrm{GE}_{\text {liver }}$, calculated as the ratio between the area below basal of EGR and the area above basal of glucose, was lower during steroid than during saline infusion, demonstrating that the ability of glucose to suppress glucose production is reduced in the presence of excess cortisol concentrations.

Rates of glucose disappearance also did not differ in the presence or absence of excess hydrocortisone (Fig. 9A). Equal rates of glucose disappearance were obtained in the presence of higher glucose concentrations, which suggests that glucose clearance was impaired. Other evidence of an impairment of glucose clearance during hydrocortisone infusion comes from the inspection of the glucose tracer data (Fig. 9B). In the present experiments, equal rates of $\left[3{ }^{3} \mathrm{H}\right]$ glucose were infused on the two study days. Therefore, the greater increment in the concentration of $\left[3-{ }^{3} \mathrm{H}\right]$ glucose during steroid than during saline infusion suggests that the tracer disappearance rate was reduced during the hydrocortisone infusion. Altered rates of glucose clearance, however, do not necessarily indicate that peripheral glucose effectiveness, GE* , is also different. In fact, glucose clearance and glucose effectiveness are related but measure slightly different aspects of glucose metabolism. According to $E q$. 3, glucose clearance is the sum of GE* and a variable component determined by the ratio between $R_{d, 0}$ (i.e., the hypothetical intercept with the $R_{d}$ axis of the $R_{d}$ vs. glucose relationship) and the time-varying glucose concentration. We found $\mathrm{GE}_{\mathrm{b}}^{*}$ to be reduced in six of eight subjects in the presence of hydrocortisone infusion; however, this reduction was not statistically significant. Also, $\mathrm{R}_{\mathrm{d}, 0}$ did not differ on the two study days. Nevertheless, because of the marked difference in the time courses of plasma glucose concentration, mean PCR was lower during hydrocortisone than during saline infusion.

All in all, the present experiments provide evidence that impaired glucose effectiveness during steroid infusion is attributable to a defect in the ability of glucose to suppress its own production. Moreover, this defect produces an elevation of the glucose level that results in impaired peripheral glucose clearance.

The finding of impaired basal glucose effectiveness during excess cortisol is in contrast to experiments by Baron et al. (4), who studied the effects of a 12-h cortisol infusion on non-insulin-mediated glucose uptake (NIMGU) (4). In these experiments, no effects of cortisol on NIMGU was demonstrated. Because glucose effectiveness in the present experiments was determined during basal insulin concentrations, and NIMGU was measured in the presence of near-zero insulin conditions, these conditions suggest that cortisol has different effects on glucose metabolism in the presence or absence of insulin.

The present experiments suggest that impaired glucose effectiveness is a contributing mechanism to glucose intolerance during conditions of excess cortisol. Various mechanisms may account for that finding. At basal insulin, glucose-mediated glucose uptake may be induced by a mass action effect facilitated by GLUT transport proteins. However, mass action is not the only mechanism. Hyperglycemia has been demonstrated to recruit insulin-independent glucose transporters (GLUT1 and GLUT2) to the cell surface via a $\mathrm{Ca}^{2+}$-dependent mechanism, which is mechanistically different from the insulin-dependent mechanism mediated via phosphatidylinositol 3-kinase (33). Furthermore, hyperglycemia has been demonstrated to induce translocation of GLUT4 transporters to the plasma membrane in muscle (17). In addition, experiments by Petersen et al. (39) have suggested that hyperglycemia inhibits hepatic glycogenolysis primarily through inhibition of glycogen phosphorylase, whereas insulin inhibits glycogenolysis primarily through stimulation of glycogen synthase. It is currently unknown how glucocorticoids interfere with these mechanisms in a 
way that ultimately leads to impaired glucose effectiveness. It is well established that glucocorticoids affect gene expression, but these hormones may also exert their effects through modulation of posttranscriptional events. Further experiments are required to determine through which pathways hypercortisolemia effects insulin action and glucose effectiveness.

\section{ACKNOWLEDGMENTS}

We thank Annette Mengel and Lene Trudsø for technical assistance, and Professor Michael Væth, Department of Biostatistics, University of Aarhus, for statistical support.

This study was supported by the Danish Research Council, the Danish Diabetes Association, National Institute of Diabetes and Digestive and Kidney Diseases Grants DK-29953 and DK-14507, and the Novo Nordisk Foundation.

\section{REFERENCES}

1. Alzaid AA, Dinneen SF, Turk DJ, Caumo A, Cobelli C, and Rizza RA. Assessment of insulin action and glucose effectiveness in diabetic and nondiabetic humans. J Clin Invest 94: 2341-2348, 1994.

2. Andersen L, Dinesen B, Jørgensen PN, Poulsen F, and Rødder ME. Enzyme immunoassay for intact human insulin in serum or plasma. Clin Chem 39: 578-582, 1993.

3. Andrews RC and Walker BR. Glucocorticoids and insulin resistance: old hormones, new targets. Clin Sci (Colch) 96: 513-523, 1999.

4. Baron AD, Wallace $\mathbf{P}$, and Brechtel G. In vivo regulation of non-insulinmediated and insulin-mediated glucose uptake by cortisol. Diabetes 36 : 1230-1237, 1987.

5. Basu A, Caumo A, Bettini F, Gelisio A, Alzaid A, Cobelli C, and Rizza RA. Impaired basal glucose effectiveness in NIDDM. Contribution of defects in glucose disappearance and production, measured using an optimized minimal model independent protocol. Diabetes 46: 421-432, 1997.

6. Beck-Nielsen H, De Pirro R, and Pedersen O. Prednisone increases in the number of insulin receptors on monocytes from normal subjects. $J$ Clin Endocrinol Metab 50: 1-4, 1980

7. Best JD, Kahn SE, Ader M, Watanabe RM, Ni TC, and Bergman RN. Role of glucose effectiveness in the determination of glucose tolerance. Diabetes Care 19: 1018-1030, 1996.

8. Bradley DC, Steil GM, and Bergman RN. Quantitation of measurement error with Optimal Segments: basis for adaptive time course smoothing. Am J Physiol Endocrinol Metab 264: E902-E911, 1993.

9. Chernow B, Alexander HR, Smallridge RC, Thomsen WR, Cook D, Fink MP, Lake CR, and Fletcher JR. Hormonal responses to graded surgical stress. Arch Intern Med 147: 1273-1278, 1987.

10. Dinneen S, Alzaid A, Miles J, and Rizza R. Metabolic effects of the nocturnal rise in cortisol on carbohydrate metabolism in normal humans. J Clin Invest 91: 2283-2290, 1993.

11. Dinneen S, Alzaid A, Miles J, and Rizza RA. Effects of the normal nocturnal rise in cortisol on carbohydrate and fat metabolism in IDDM. Am J Physiol Endocrinol Metab 268: E595-E603, 1995.

12. Dinneen S, Gerich J, and Rizza R. Carbohydrate metabolism in noninsulin-dependent diabetes mellitus. N Engl J Med 327: 707-713, 1992.

13. Dinneen SF. The effects of glucocorticoid hormones on substrate metabolism. In: Clinical Research in Diabetes and Obesity, Part I: Methods, Assessment and Metabolic Regulation. Totowa, NJ: Humana, 1997, p. 243-257.

14. Fantus IG, Ryan J, Hizuka N, and Gorden P. The effect of glucocorticoids on the insulin receptor: an in vivo and in vitro study. $J$ Clin Endocrinol Metab 52: 953-960, 1981.

15. Finegood DT and Tzur D. Reduced glucose effectiveness associated with reduced insulin release: an artifact of the minimal-model method. Am J Physiol Endocrinol Metab 271: E485-E495, 1996.

16. Fleig WE, Noether-Fleig G, Roeben H, and Ditschuneit H. Hormonal regulation of key gluconeogenic enzymes and glucose release in cultured hepatocytes: effects of dexamethasone and gastrointestinal hormones on glucagon action. Arch Biochem Biophys 229: 368-378, 1984.

17. Galante P, Mosthaf L, Kellerer M, Berti L, Tippmer S, Bossenmaier B, Fujiwara T, Okuno A, Horikoshi H, and Haring HU. Acute hyperglycemia provides an insulin-independent inducer for GLUT4 translocation in $\mathrm{C}_{2} \mathrm{C}_{12}$ myotubes and rat skeletal muscle. Diabetes 44: 646$651,1995$.
18. Gill A, Johnston DG, Ørskov H, Batstone GF, and Alberti KGMM. Metabolic interactions of glucagon and cortisol in man-studies with somatostatin. Metabolism 31: 305-311, 1982.

19. Goldstein RE, Reed GW, Wasserman DH, Williams PE, Lacy DB, Buckspan R, Abumrad NN, and Cherrington AD. The effect of acute elevations in plasma cortisol levels on alanine metabolism in the conscious dog. Metabolism 41: 1295-1303, 1992.

20. Goldstein RE, Wasserman DH, McGuinness OP, Lacy DB, Cherrington AD, and Abumrad NN. Effects of chronic elevation in plasma cortisol on hepatic carbohydrate metabolism. Am J Physiol Endocrinol Metab 264: E119-E127, 1993.

21. Heaney AP, Harper R, Ennis C, Rooney DP, Sheridan B, Atkinson $\mathbf{A B}$, and Bell PM. Insulin action and hepatic glucose cycling in Cushing's syndrome. Clin Endocrinol 46: 735-743, 1997.

22. Kahn CR, Goldfine ID, Neville DM, and De Meyts P. Alterations in insulin binding induced by changes in vivo in the levels of glucocorticoids and growth hormone. Endocrinology 103: 1054-1066, 1978.

23. Karnieli E, Cohen P, Barzilai N, Ish-Shalom Z, Armoni M, Rafaelov $\mathbf{R}$, and Barzilai D. Insulin resistance in Cushing's syndrome. Horm Metab Res 17: 518-521, 1985.

24. Landau BR. Methods for measuring glycogen cycling. Am J Physiol Endocrinol Metab 281: E413-E419, 2001.

25. Landau BR, Wahren J, Chandramouli V, Schumann WC, Ekberg K, and Kalhan SC. Contribution of gluconeogenesis to glucose production in the fasted state. J Clin Invest 98: 378-385, 1996.

26. Matthews DR, Hosker JP, Rudenski AS, Naylor BA, Treacher DF, and Turner RC. Homeostasis model assessment: insulin resistance and beta-cell function from fasting plasma glucose and insulin concentrations in man. Diabetologia 28: 412-419, 1985.

27. Matthews JN, Altman DG, Campbell MJ, and Royston P. Analysis of serial measurements in medical research. Br Med J 300: 230-235, 1990.

28. McMahon M, Gerich J, and Rizza R. Effects of glucocorticoids on carbohydrate metabolism. Diabetes Metab Rev 4: 17-30, 1988.

30. Murton SA, Tan ST, Prickett TCR, Frampton C, and Donald RA. Hormone responses to stress in patients with major burns. Br J Plast Surg 51: 388-392, 1998.

31. Nielsen MF, Basu R, Wise S, Caumo A, Cobelli C, and Rizza RA. Normal glucose-induced suppression of glucose production but impaired stimulation of glucose disposal in type 2 diabetes. Evidence for a concentration-dependent defect in uptake. Diabetes 47: 1735-1747, 1998.

32. Nielsen MF, Nyholm B, Caumo A, Chandramouli V, Schumann WC, Cobelli C, Landau BR, Rizza RA, and Schmitz O. Prandial glucose effectiveness and fasting gluconeogenesis are unaltered in insulin resistant first-degree relatives of patients with type 2 diabetes. Diabetes 49: 21352141, 2000.

33. Nolte LA, Rincon J, Odegaard Wahlstrom E, Craig BW, Zierath JR, and Wallberg-Henriksson $\mathbf{H}$. Hyperglycemia activates glucose transport in rat skeletal muscle via a $\mathrm{Ca}^{2+}$ dependent mechanism. Diabetes 44: 1345-1348, 1995.

34. Nosadini R, Del Prato S, Tiengo A, Valerio A, Muggeo M, Opocher G, Mantero F, Duner E, Marescotti C, Mollo F, and Belloni F. Insulin resistance in Cushing's syndrome. J Clin Endocrinol Metab 57: 529-536, 1983.

35. Offner PJ, Moore EE, and Ciesla D. The adrenal response after severe trauma. Am J Surg 184: 649-653, 2002.

36. Olefsky J. Effect of dexamethasone on insulin binding, glucose transport and glucose oxidation of isolated rat adipocytes. J Clin Invest 56: 1499 $1508,1975$.

37. Page R, Boolell M, Kalfas A, Sawyer S, Pestell R, Gleen W, and Alford F. Insulin secretion, insulin sensitivity and glucose-mediated glucose disposal in Cushing's disease: a minimal model analysis. Clin Endocrinol 35: 509-517, 1991.

38. Perseghin G, Caumo A, Caloni M, Testolin G, and Luzi L. Incorporation of the fasting plasma FFA concentration into QUICKI improves its association with insulin sensitivity in nonobese individuals. J Clin Endocrinol Metab 86: 4776-4781, 2001.

39. Petersen KF, Laurent D, Rothman DL, Cline GW, and Shulman GI. Mechanism by which glucose and insulin inhibit net hepatic glycogenolysis in humans. J Clin Invest 101: 1203-1209, 1998.

40. Quon MJ, Cochran C, Taylor SI, and Eastman RC. Non-insulinmediated glucose disappearance in subjects with IDDM. Discordance between experimental results and minimal model analysis. Diabetes 43: 890-896, 1994.

41. Rizza RA, Mandarino L, and Gerich J. Cortisol induced insulin resistance in man: impaired suppression of glucose production and stimulation 
of glucose utilization due to a post-receptor defect of insulin action. J Clin Endocrinol Metab 54: 131-138, 1982.

42. Rooney DP, Neely RDG, Cullen C, Ennis CN, Sheridan B, Atkinson AB, Trimble ER, and Bell PM. The effect of cortisol on glucose/glucose6-phosphate cycle activity and insulin action. J Clin Endocrinol Metab 77: 1180-1183, 1993.

43. Samra JS, Clark ML, Humphreys SM, MacDonald I, Bannister PA, and Frayn KN. Effects of physiological hypercortisolemia on the regulation of lipolysis in subcutaneous adipose tissue. J Clin Endocrinol Metab 83: 626-631, 1998.

44. Sasaki K, Cripe TP, Koch SR, Andreone TL, Peterson DD, Beale EG, and Granner DK. Multihormonal regulation of phosphoenolpyruvate carboxykinase gene transcription. J Biol Chem 259: 15242-15251, 1984.
45. Steele R, Wall JS, De Bodo RC, Altszuler N, Kiang SP, and Bjerknes C. Measurement of size and turnover rate of body glucose pool by the isotope dilution method. Am J Physiol 187: 15-24, 1956.

46. Turner RC, Holman RR, Matthews D, Hockaday TDR, and Peto J. Insulin deficiency and insulin resistance interaction in diabetes: estimation of their relative contribution by feedback analysis from basal plasma insulin and glucose concentrations. Metabolism 28: 10861096, 1979.

47. Wang P, Ba ZF, Jarrar D, Cioffi WG, Bland KI, and Chaudry IH. Mechanism of adrenal insufficiency following trauma and severe hemorrhage: role of hepatic 11beta-hydroxysteroid dehydrogenase. Arch Surg 134: 394-401, 1999.

48. Zennaro MC. Syndromes of glucocorticoid and mineralocorticoid resistance. Eur J Endocrinol 139: 127-138, 1998.

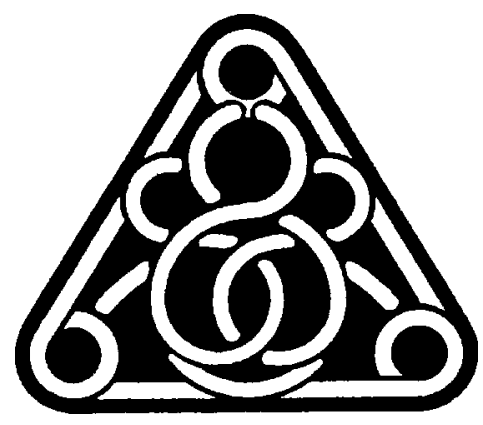

